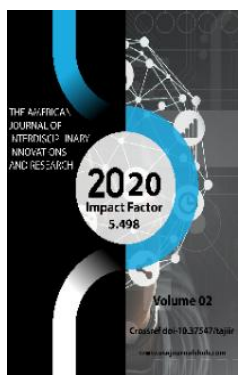

Journal Website: http://usajournalshub.c om/index,php/tajiir

Copyright: Original content from this work may be used under the terms of the creative commons attributes 4.0 licence.

\section{Heat Engineering Heterogeneity Of The Outer Walls Of Earthquake-Resistant Buildings}

\author{
Shipacheva E.V. \\ Tashkent State Transport University, Uzbekistan \\ Pirmatov R. Kh. \\ Tashkent State Transport University, Uzbekistan
}

Turdalieva M.K.

Tashkent Institute Of Architecture And Civil Engineering, Uzbekistan

\title{
ABSTRACT
}

When assessing the level of energy efficiency of civilian buildings, a special place is given to establishing the level of thermal protection of their external enclosing structures. Significant discrepancies in the results of theoretical and experimental studies of heat fluxes through the outer walls of buildings erected in seismic areas are associated with the design features of fences - the presence of reinforced concrete elements in them: anti-seismic belts at the level of floors, cores at intersections of walls and along the edges of large window openings ... In addition, in recent years, external walls have become widespread, which are filling of bricks or aerated concrete blocks between the main structural elements of the frame - monolithic reinforced concrete columns and crossbars.

The introduction of reinforced concrete elements into the structure of the external wall fencing provides strength, rigidity and stability of buildings, guarantees its seismic resistance. At the same time, reinforced concrete inclusions are significant "cold bridges" in warmer brick or aerated concrete masonry. Such heat engineering heterogeneity of earthquake-resistant outer walls significantly complicates the process of determining their heat-shielding properties. This, in turn, leads to errors in the design of heating systems, which inevitably affects the thermal comfort of the premises, the formation of condensation and mold zones in the cold zones of the inner surface of the fences.

The article presents the results of theoretical and experimental studies to determine the heatshielding properties of external heat-engineering heterogeneous walls of earthquake-resistant buildings. The most reliable method for calculating the reduced resistance to heat transfer of an inhomogeneous external structure and the coefficient of its thermal inhomogeneity have been established. 


\section{KEYWORDS}

Energy efficiency, thermal protection, cold bridge, thermal engineering heterogeneity, heat transfer resistance, outer walls, reinforced concrete inclusions, thermal comfort

\section{INTRODUCTION}

A significant increase in energy prices in the world community was the reason for the tightening of requirements for saving fuel and energy resources in all sectors of the economy $[1,2,3]$. One of the most energy-intensive sectors of the national economy, consuming up to $40 \%$ of the country's fuel and energy resources, is the housing and utilities sector. At the same time, as noted by numerous researchers $[4,5,6]$, the real potential of energy saving in this area can be from 20 to $30 \%$. The solution to this problem is associated with increased requirements for the quality of building design and, first of all, its enclosing structures, since design errors lead to a decrease in the heat-shielding properties of fences and an increase in operating energy costs $[7,8]$. In this regard, research aimed at increasing the level of energy efficiency of civil buildings and improving methods for assessing the heat-shielding properties of external enclosing structures is of particular importance.

\section{THEORETICAL AND EXPERIMENTAL RESEARCH}

When assessing the level of energy efficiency of civilian buildings, a special place is given to establishing the level of thermal protection of their external enclosing structures. Significant discrepancies in the results of theoretical and experimental studies of heat fluxes through the outer walls of buildings erected in seismic areas are associated with the design features of the fences - the presence of the structure of reinforced concrete elements in them: anti- seismic belts at the floor level, cores at intersections of walls and along the edges of large window openings [nine]. In addition, in recent years, external walls have become widespread, which are filling of bricks or aerated concrete blocks between the main structural elements of the frame - monolithic reinforced concrete columns and crossbars.

The introduction of reinforced concrete elements into the structure of the external wall fencing provides strength, rigidity and stability of buildings, guarantees its seismic resistance. At the same time, reinforced concrete inclusions are significant "cold bridges" in warmer brick or aerated concrete masonry. Such heat engineering heterogeneity of earthquake-resistant outer walls significantly complicates the process of determining their heat-shielding properties. This, in turn, leads to errors in the design of heating systems, which inevitably affects the thermal comfort of the premises, the formation of condensation and mold zones in the cold zones of the inner surface of the fences.

The normative document [10] provides for two approaches to the determination of the reduced resistance to heat transfer of heat-engineering heterogeneous external walls, depending on their design solution. In the first case, it is proposed to cut the wall and determine the thermal resistance first with planes parallel and then perpendicular to the heat flow. In this case, the reduced thermal resistance is determined by the formula:

$$
R_{K}^{h t}=\frac{R_{a}+2 R_{b}}{3}
$$


where $R_{a}$ - thermal resistance of a structure when cut by planes parallel to the heat flux,

$R_{b}$ - thermal resistance of a structure when cutting it by planes perpendicular to the heat flow. $R_{a}$ and $R_{b}$ calculated according to the formulas given in [10]. The calculation turns out to be quite time consuming.

If $R_{a}$ more $1,25 R_{6}$ or the wall structure has protrusions, then it is recommended to use temperature fields to determine the reduced thermal resistance in [10]. This implies either the implementation of experimental studies, or the use of special calculation programs that make it possible to determine the average temperatures on the inside $\left(\tau_{\text {в.ср }}\right)$ and outdoor $\left(\tau_{\text {н.ср }}\right)$ surfaces of the structure. Then it is assumed to calculate the magnitude of the heat flux passing through the outer fence by the formula:

$$
Q^{\text {calc }}=\alpha_{B}\left(t_{B}-\tau_{\text {B.cp }}\right)=\alpha_{H}\left(t_{H}-\tau_{\text {H.cp }}\right) \text {, }
$$

where $\alpha_{\mathrm{B}}$ - heat transfer coefficient of the inner surface of the building envelope, $a_{H}$ - heat transfer coefficient for winter operating conditions of the outer surface of the enclosing structure, $t_{B}$ - design indoor air temperature, $t_{H}$ - design outdoor temperature.

Determination of the reduced resistance to heat transfer of a non-uniform enclosing structure $\left(R_{0}\right)$ in this case, according to [10], it is produced by the formula:

$$
R_{o}=\frac{t_{B}-t_{H}}{q^{\text {calc }}}
$$

The most accurate determination of the reduced resistance to heat transfer of a heatengineering heterogeneous wall structure makes it possible to establish a really reasonable thickness of the insulation to ensure the required level of thermal protection of buildings. It would seem that the problem is completely solvable and does not require any additional research. However, the question is precisely in ensuring a sufficiently accurate determination of the thermal properties of fences, since the generalization of data on the value of the actual energy consumption of residential buildings of different years of construction shows that the specific consumption of thermal energy in old panel houses and modern residential buildings with two-layer walls of brickwork on cement sandy mortar and facing brick practically does not differ. One of the reasons for this phenomenon is that the structures of two-layer walls are often overestimated in terms of their thermal protection parameters.

In this regard, we have calculated the resistance to heat transfer of a two-layer wall structure by various known methods in order to establish their equivalence, on the one hand, and to identify the actual effect of "cold bridges" on the heat-shielding properties of fences, on the other hand.

For research, the structure of the outer wall in a building with a monolithic reinforced concrete frame was adopted, which is based on the floor by floor on reinforced concrete floors and consists of two layers (Fig. 1):

- an internal non-bearing layer made of brickwork on a cement-sand mortar with a thickness of $380 \mathrm{~mm}$ (taking into account the mortar for fixing the facing layer, a thickness of $390 \mathrm{~mm}$ was taken);

- the outer facing layer of facing brick, one brick thick. 


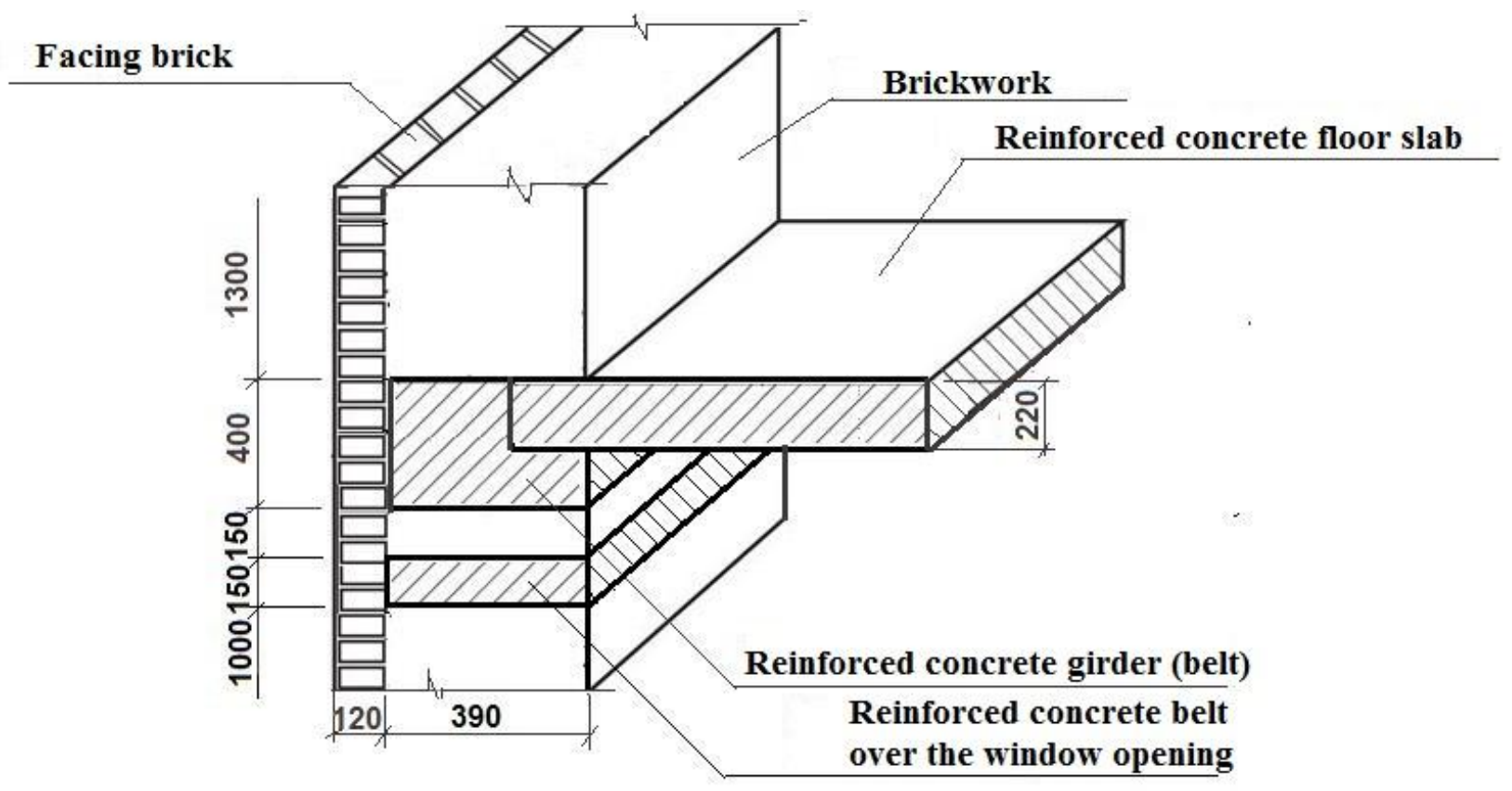

Fig.1. Constructive solution of the outer wall of the building

The reduced resistance to heat transfer of an inhomogeneous outer wall was determined for the intermediate floor and without taking into account the presence of windows. The design diagram of a fragment of the outer wall is shown in Fig. 2.

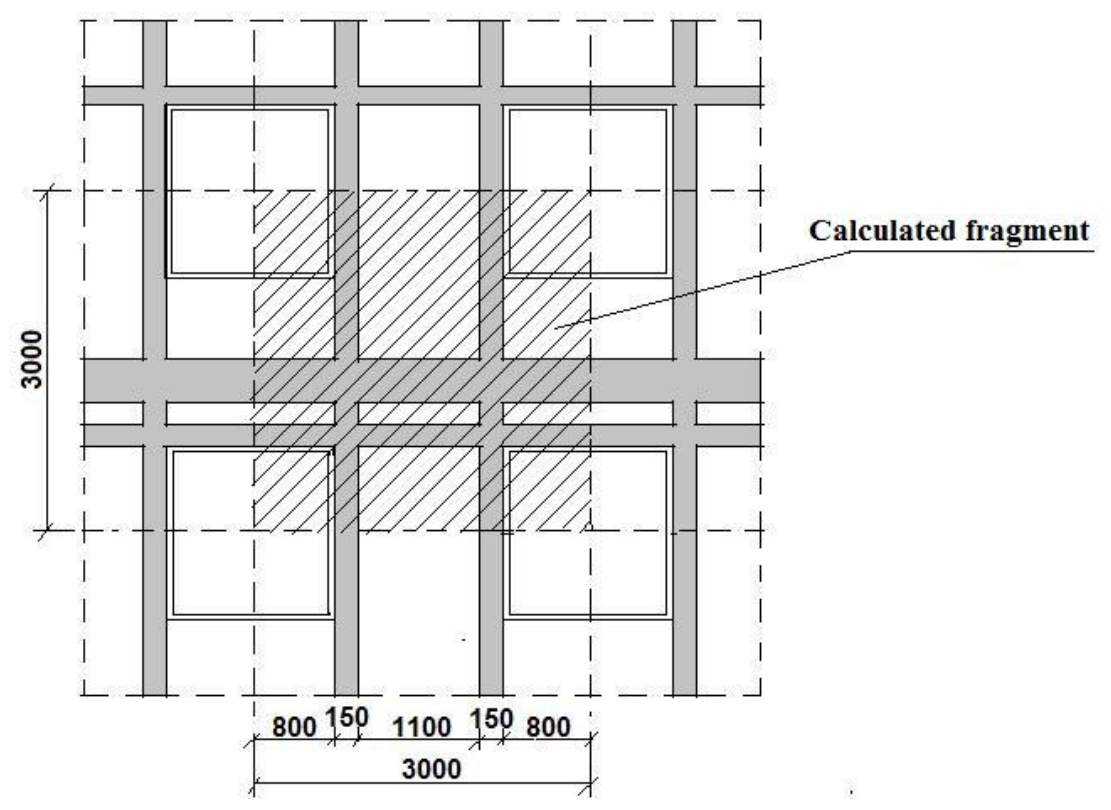

Fig. 2. Scheme of the calculated fragment of the wall of a residential building 
Thermal characteristics of materials and boundary conditions were adopted according to the normative document [10]. The masonry of the walls was taken from ordinary bricks on a cementsand mortar, and the facing layer was made of ceramic hollow bricks with a density of $1300 \mathrm{~kg} / \mathrm{m}^{3}$ on a cement-sand mortar.

According to the methodology given in the normative document [10], the values of the thermal resistance of the outer wall were determined:

- when cutting it by planes parallel to the heat flow $R_{a}$;

- when cutting it by planes perpendicular to the heat flow $R_{b}$.

The accepted design scheme is shown in Fig. 3. The calculation was carried out on a site without window openings.

\section{Facing brick masonry}

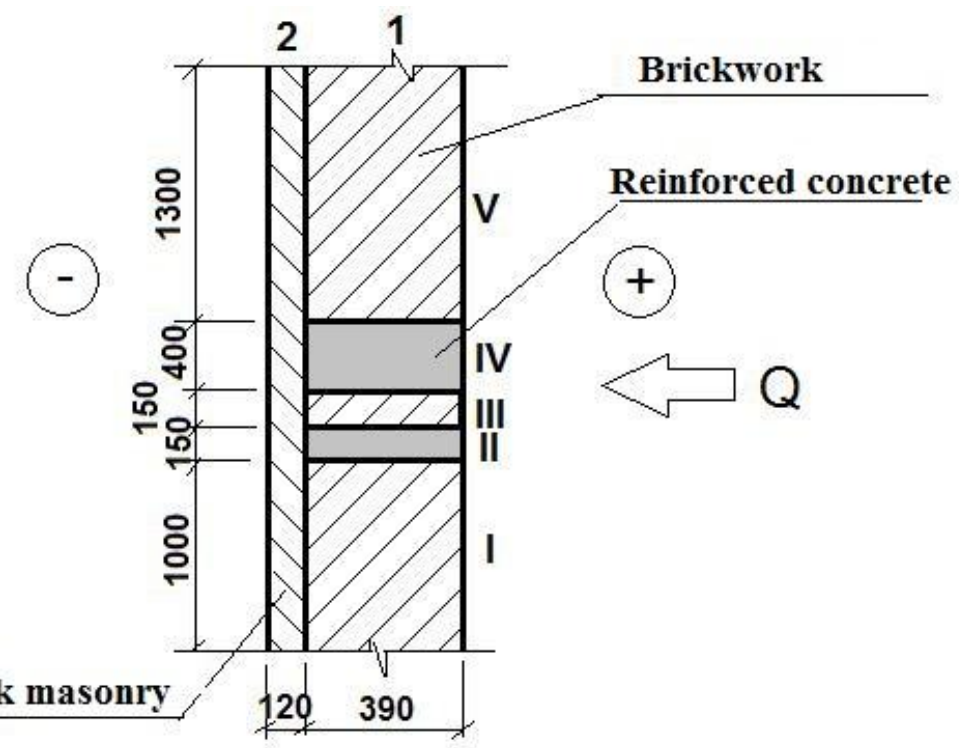

Fig. 3. Calculation scheme for determining the reduced thermal resistance

1,2 - areas perpendicular to the heat flow; I -V - sections parallel to the heat flow; $Q$ heat flow

Since, as a result of the calculation, it was determined that $R_{a}=0,558\left[\frac{\mathrm{M}^{2} \cdot{ }^{0} \mathrm{C}}{\mathrm{Bm}}\right]<R_{b}=0,653\left[\frac{\mathrm{M}^{2} \cdot{ }^{0} \mathrm{C}}{\mathrm{Bm}}\right]$, then the reduced thermal resistance of a heat-engineering non-uniform outer wall was determined by the formula (1):

$$
R_{K}^{t r}=\frac{0,558+2 * 0,653}{3}=0,621\left[\frac{\mathrm{M}^{2} \cdot{ }^{0} \mathrm{C}}{\mathrm{Bm}}\right],
$$

At the same time, the reduced resistance to heat transfer of the outer wall was:

$$
R_{0}=\frac{1}{\alpha_{B}}+R_{K}^{t r}+\frac{1}{\alpha_{H}}=\frac{1}{8,7}+0,621+\frac{1}{23}=0,779\left[\frac{M^{2} \cdot{ }^{0} \mathrm{C}}{B m}\right],
$$

$a_{H}, a_{B}$ - heat transfer coefficients, respectively, on the outer and inner surfaces of the wall, taken according to the regulatory document [10].

The coefficient of thermal engineering heterogeneity was $r=0,823$. 
Taking into account that in many advanced countries of the world, in order to improve the accuracy of determining heat losses through heterogeneous external enclosing structures of buildings, they switched to the method of calculating the reduced resistance to heat transfer, based on streamlining the accounting of additional heat losses through heat-conducting inclusions [11], the specified technique. For the selected fragment of the outer wall of the building (Fig. 2), specific heat losses through the "cold bridges" were determined under the same initial conditions.

Calculation of specific heat losses through the "cold bridges" of the outer wall consisted of the following stages:

- marking of nodes on a fragment of an external wall containing heat-conducting inclusions and determination of their geometric dimensions;

- determination of the temperature field of a unit with a heat-conducting connection;

- calculation of specific heat losses through a heat-conducting connection [12].

The designation of the design nodes on the selected wall fragment is given in Fig. 4.
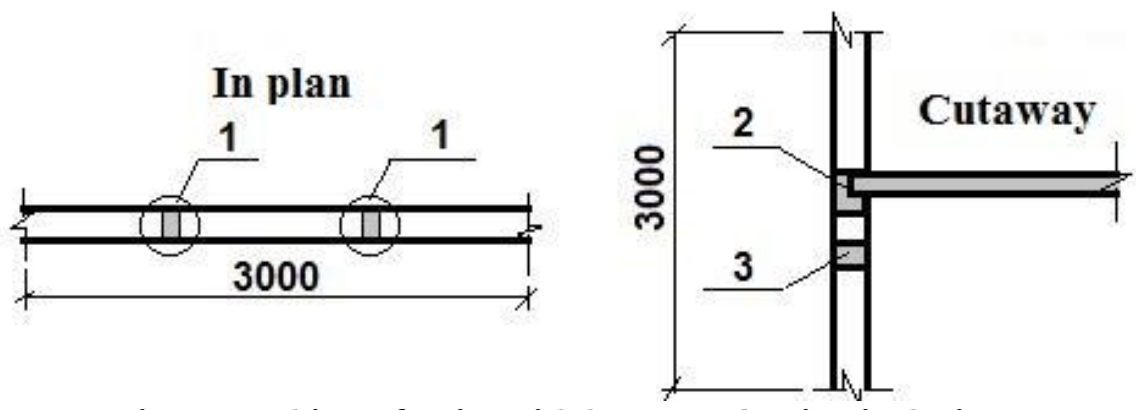

Fig. 4. Marking of units with heat-conducting inclusions

In accordance with the geometric dimensions of a fragment of the building wall (Fig. 2), the geometric and specific geometric indicators of elements with heat-conducting inclusions were determined, which are presented in Table. 1.

Table 1. Geometric characteristics of units with heat-conducting inclusions

\begin{tabular}{|l|l|l|c|c|}
\hline $\begin{array}{c}\text { Node } \\
\text { markin } \\
\mathrm{g}\end{array}$ & \multicolumn{1}{|c|}{ Node type } & Brief description of the node & $\begin{array}{c}\text { Geometric } \\
\text { indicator }\end{array}$ & $\begin{array}{c}\text { Specific } \\
\text { geometric } \\
\text { indicator }\end{array}$ \\
\hline 1 & Linear vertical & $\begin{array}{l}\text { Junction of the outer wall to } \\
\text { the core }\end{array}$ & $4,9 \mathrm{M}$ & $0,5444 \mathrm{M} / \mathrm{M}^{2}$ \\
\hline 2 & Linear horizontal & $\begin{array}{l}\text { Adjacency of the outer wall } \\
\text { to the interfloor ceiling and } \\
\text { seismic belt }\end{array}$ & $3,0 \mathrm{M}$ & $0,3333 \mathrm{M} / \mathrm{M}^{2}$ \\
\hline 3 & Linear horizontal & $\begin{array}{l}\text { Adjoining the outer wall to } \\
\text { the belt above the window } \\
\text { opening }\end{array}$ & $3,0 \mathrm{M}$ & $0,3333 \mathrm{M} / \mathrm{M}^{2}$ \\
\hline
\end{tabular}


Table 2.Calculations of the temperature fields of the nodes with heat-conducting inclusions were carried out using the TEMPER 3D computer program

\begin{tabular}{|c|c|c|c|c|}
\hline $\begin{array}{c}\text { Construction element } \\
\text { № / node }\end{array}$ & $\begin{array}{l}\text { Specific } \\
\text { geom. } \\
\text { index }\end{array}$ & $\begin{array}{c}\text { Specific heat } \\
\text { loss, BT } /\left(\mathrm{M}^{2} \cdot{ }^{0} \mathrm{C}\right)\end{array}$ & $\begin{array}{l}\text { Specific heat flux } \\
\text { due to the element, } \\
\qquad \mathrm{BT} /\left(\mathrm{M}^{2} \cdot{ }^{0} \mathrm{C}\right)\end{array}$ & $\begin{array}{c}\text { The share of } \\
\text { the total heat } \\
\text { flux through } \\
\text { the fragment, } \\
\%\end{array}$ \\
\hline Flat element /- & $a=1 \mathrm{M}^{2} / \mathrm{M}^{2}$ & $\mathrm{U}_{1}=1,0571$ & 1,0571 & 63,3 \\
\hline Linear vertical /1 & $\begin{array}{c}l_{1}=0,5444 \\
\mathrm{M} / \mathrm{M}^{2}\end{array}$ & $\Psi_{1}=0,3356$ & 0,1827 & 11,0 \\
\hline Linear horizontal /2 & $\begin{array}{c}l_{2}=0,3333 \\
\mathrm{M} / \mathrm{M}^{2}\end{array}$ & $\Psi_{2}=0,9170$ & 0,3056 & 18,4 \\
\hline \multirow[t]{2}{*}{ Linear horizontal /3 } & $\begin{array}{c}l_{3}=0,3333 \\
\mathrm{M} / \mathrm{M}^{2}\end{array}$ & $\Psi_{3}=0,3636$ & 0,1212 & 7,3 \\
\hline & & & $1 / R_{п р}=1,661$ & 100 \\
\hline
\end{tabular}

In accordance with the performed calculation, the reduced resistance of a non-uniform wall of a residential building was $0,602 \mathrm{~m}^{2} \cdot{ }^{\circ} \mathrm{C} / \mathrm{BT}$ with the coefficient of heat engineering heterogeneity $r=0,636$.

Comparison of the results of calculations using the two methods showed that the discrepancy is quite significant and amounts to $22,7 \%$.

To establish the most accurate method, field studies were carried out. A grid with $10 \times 10 \mathrm{~cm}$ cells was applied to the selected section of the wall from the outside.At the nodes of the grid, the temperature was measured on the surfaces of the wall fence using a pyrometer in the evening in order to avoid exposure to the structure of direct and reflected sunlight. The obtained measurement results were processed and, by averaging, the temperature on the outer surface of the building wall was determined, which was: $+4,3^{\circ} \mathrm{C}$. At the same time, the external temperature was fixed at $+3^{\circ} \mathrm{C}$, and the internal air temperature was $+20,5^{\circ} \mathrm{C}$. As a result, the actual value of the reduced resistance to heat transfer of the outer wall of the building was determined, which was $R_{0}=0,581\left[\frac{\mathrm{m}^{2} \cdot{ }^{0} \mathrm{C}}{\mathrm{Bm}}\right]$.

The discrepancies in the values of the reduced resistance to heat transfer of a heat-engineering non-uniform outer wall, obtained experimentally and by the two methods used, amounted to: $25 \%$ and $3,5 \%$.

\section{CONCLUSION}

The studies carried out have proved that the outer small-element walls of earthquakeresistant buildings have significant thermal engineering heterogeneity, which significantly affects the heat-shielding properties of the outer shell of the building.

Comparison of the results of theoretical calculations and a full-scale experiment, as well as data from previously performed studies $[13,14]$, confirmed that the transition to mandatory accounting for the values of specific heat losses of enclosing structures when determining the thermal properties of the outer shell of buildings is advisable. It will improve the quality of assessing the energy characteristics of buildings, as well as the design of their enclosing structures and heating systems. 


\section{REFERENCES}

1. Bridge, G. Bouzarovski, S. Bradshaw, M. \& Eyre, N. (2013). Geographies of energy transition: space, place and the lowcarbon economy. Energy Policy 53: 331340.

URL:

http://www.sciencedirect.com/science/art icle/pii/S0301421512009512

2. Timmons, D. Harris, J. M. \& Roach, B. (2014). The Economics of Renewable Energy. Retrieved From: https://ase.tufts.edu/gdae/education_mat erials/modules/RenewableEnergyEcon. pdf.

3. Frankfurt School \& United Nations Environment Programme (FS-UNEP Collaborating Centre). (2018). Global Trends in Renewable Energy Investment 2018. Retrieved From: https://europa.eu/capacity4dev

4. Ke, M. T., Yeh, C. H., and Jian, J. T. (2013). Analysis of building energy consumption parameters and energy savings measurement and verification by applying eQUEST software. Energy and Buildings, 61, 100-107.

5. Z. Yang, B. Liu, Haibe Zhao (2004) Energy Saving in Building Construction in China: A Review// International Journal of Green Energy

6. Tabunshchikov Yu. A. Construction concepts of buildings of the XXI century in the field of heat supply and air conditioning // AVOK. - Moscow: 2005.№ 4. 5-14 pp.

7. Danilevsky, L.N., Pilipenko, V.M. Experience in the construction and operation of the first energy efficient building in the Republic of Belarus and development prospects / L.N. Danilevsky // Collection of RAASN, - Moscow: 2011. pp. 37-45.

8. Gossard, D.; Lartigue, B.; Thellier, F. Multiobjective optimization of a building envelope for thermal performance using genetic algorithms and artificial neural network. Energy Build. 2013, 67, 253-260. [Google Scholar] [CrossRef]

9. KMK 2.01.03-96 Construction in seismic regions - Tashkent: AQATM / - 1996.

10. KMK 2.01.04-2018 Construction heat engineering - Tashkent: AQATM / - 2019.

11. TKP 45-2.04-43-2006 Construction heat engineering. Building design standards Minsk, 2006

12. SP. 1325800.2015 Fencing structures of buildings. Characteristics of heat engineering heterogeneities - Moscow: Ministry of Construction of Russia, 2015.67 p.

13. Shchipacheva E.V., Kamilova M.K. Modern methods for calculating the heatshielding properties of heat-engineering non-uniform external walls of buildings // "Architecture. Construction. Design ", Tashkent: 2019, No. 1, pp. 63-65.

14. Shchipacheva E.V., Pirmatov R.Kh. Kamilova M.K. On the heat-shielding properties of heat-engineering heterogeneous external walls of buildings I Proceedings of the All-Russian Conf. "Function, design, environment in the architecture of buildings" - Moscow: MGSU, 25-26 Apr. 2019, S. 119-120. 